pressed for the former, and as the book weighs seven pounds it is obviously far too bulky for the latter. The information is grouped under genera, which may be satisfactory for monotypic or small genera (which get a disproportionate amount of space) but which make it necessary, in a large genus like Accipiter and Falco, to wade through many pages to extract little bits of information on a particular species; also there is much to criticise in the drawings that adorn this section.

The outstanding feature of the book is the magnificent series of action photographs by Shelly Grossman. Admittedly most of these are of captive birds, and where photographs of wild birds occur they are often undistinguished unless by other photographers such as Eric Hosking. But only by the use of trained captive birds could one hope to obtain some of these action sequences, for instance those of the horned owl and a snake, and a red-tailed hawk and opossum, and they have been intelligently selected to show features of the basic biology, for instance the use of the cutting tool on the mandible in Falco.

Quite evidently this book represents an enormous amount of work, and it will contain enough material on raptors to satisfy many people and perhaps stimulate others. But it seems a pity that the authors did not concentrate on the photographic material with enlarged sections on habits especially as revealed by captive birds, without attempting to do the impossible and include information on all species. This certainly cannot be done without much greater compression and terseness than is found here.

L. H. BROWN.

\title{
The Birds of Natal and Zululand, by P. A. Clancey. Oliver $\mathcal{G}$ Boyd, 84s.
}

This book is a noteworthy achievement. It will be indispensable to the student of ornithology, and welcomed by all interested in South African birds. It reflects the greatest credit on the energy of the author, also on the printers. Detailed plumage descriptions are followed by field notes, with reference to nests and breeding seasons, but no account of the eggs. Subspecies are treated on a specific basis and the impression is that attention has been less to field data than to taxonomic considerations. The bird illustrations are all the author's work and in the main are colourful and pleasing, but it is a pity that more species did not receive colour treatment instead of grouping individurals in one species.

Natal's extensive grassland's are divided into types according to altitude, and are distinctive in the avifaunal populations. The excellent photographs of the countryside include three of the "highveld sourveld" but regrettably none of the midland "nkonkoni" grassveld. The country descends rapidly from 10,000 feet to sea-level and its zoogeography is of great interest; so it is unfortunate that the map, instead of being topographical is reproduced from a tourist road guide. There are some distributional omissions, for the author has not yet investigated certain areas, as shown by the addenda which result largely from a recent paper on a part of the Drakensberg foothills, and there will be some disagreement with certain subspecific divisions. Small imperfections, however, do not alter a very readable and most competent volume, which is a valuable contribution to the biological literature of an interesting region.

J. VINCENT.

\section{About Sharks and Shark Attack, by David H. Davies. Routledge \& Kegan Paul, 40s.}

The picture of 'the triangular fin of a shark cutting through the water' is a stock element of many thrillers; in popular imagination the savagery of the shark is unequalled, but the true facts about sharks' attacks on man are less well known. In this book Dr. Davies describes in detail- 
including exceedingly gory photographs of some of the victims-the history of shark attacks on bathers in South African waters and the steps taken to deal with them. In absolute terms shark attacks are very rare; over the past twenty years in Natal an average of fewer than one person a year has been killed by sharks compared with 175 deaths on Natal roads in four months of 1963 (though a more interesting comparison would be with bathing fatalities from other causes). However, an outbreak of attacks in 1957, including two fatalities, drove many visitors away from the south coast of Natal, and caused serious economic recession in this area, which is greatly dependent on tourism.

The most effective of a range of measures against sharks has been netting off the bathing beaches. These nets do not form an impenetrable barrier, but they do catch the sharks as they move along the shore, and, judging by the catch records, greatly reduce the population of sharks in the area. A more fundamental solution may in future be obtained from the work of the research institutions including the Anti-shark Research Association set up under the South African Association for Marine Biological Research, of which Dr. Davies is Director; their activities are briefly described in an appendix to this interesting book.

$$
\text { J. A. GULLAND. }
$$

\section{The Insects, by Peter Farb; The Fishes, by F. D. Ommanney;} The Birds, by Roger Tory Peterson; The Mammals, by Richard Carrington. Life Nature Library, Time-Life International, 32s. 6d. each.

These four books, all superbly illustrated, well indexed and with good bibliographies, continue the Life Nature Library of which eight volumes have already been briefly reviewed in ORYX. The danger in this series is that because each subject is too vast to be dealt with adequately, even in outline, in the space available, the wonderful illustrations will completely dominate the excellent essays. Consequently the book lies around, genuinely admired but only cursorily studied, until it takes a place on the bookshelf from which it descends only temporarily to interest some young visitor.

But these fine books have a higher function than passing entertainment and occasional reference. Their true use is to arouse and maintain interest in the marvellous panorama of nature, an interest which exists in nearly every person, but too often remains too long dormant. So, give a volume, or the whole series to someone, child or adult, whose love of nature you would kindle or encourage. You will surely be rewarded by his reaction.

c. L. BOYLE.

\section{Dictionary of Herpetology, by James A. Peters. Hafner, New York, 92s.}

Anyone actively involved with herpetological research will automatically require a copy of James Peters's new dictionary. As a specialised reference work it will be of value for many years to come. Peters is well qualified to produce this collection of terms and definitions, having been active in the field of herpetology for over twenty years. He has collected reptiles and amphibians in India, Africa, and throughout the Americas, and is at present the Secretary of the American Society of Ichthyologists and Herpetologists. Over the years he has built up an elaborate card index system of technical terms and words and has scanned over 10,000 papers and books in a brave attempt to achieve as comprehensive a compilation as possible. Inevitably there will be a few missing terms, but the general herpetologist will find little to quibble with. Altogether there are over 3,000 definitions, in most cases with the original reference, where the 